\section{Pain Asymbolia}

Stephen T. Wegener ${ }^{1}$ and Mathew Jacobs ${ }^{2}$ ${ }^{1}$ Division of Rehabilitation Psychology and Neuropsychology Department of Physical Medicine and Rehabilitation, The Johns Hopkins School of Medicine, Baltimore, MD, USA

${ }^{2}$ State College, Pennsylvania, United States

\section{Definition}

Pain asymbolia is a condition in which pain is perceived, but with an absence of the suffering that is normally associated with the pain experience. Individuals with pain asymbolia still identify the stimulus as painful but do not display the behavioral or affective reactions that usually accompany pain; no sense of threat and/or danger is precipitated by pain.

\section{Current Knowledge}

Pain asymbolia has been associated with damage to the insular cortex and the projections to the cingulate gyrus. Processing of pain involves the insular cortex receiving sensory input including pain signals from the skin and viscera. The insular cortex projects to parts of the limbic system, which gives rise to the affective component of pain. In pain asymbolia, the sensory-discriminative component of the pain processing is intact, whereas the affective-motivational component is impaired.

\section{Cross-References}

Insular Cortex

$\checkmark$ Pain

\section{References and Readings}

Gatchel, R. J., Peng, Y. B., Peters, M. L., Fuchs, P. N., \& Turk, D. C. (2007). The biopsychosocial approach to chronic pain: Scientific advances and future directions. Psychological Bulletin, 133(4), 581-624.

Ramachandran, V. S. (1998). Consciousness and body image: Lessons from phantom limbs, Capgras syndrome and pain asymbolia. Philosophical Transactions of the Royal Society of London. Series B, Biological Sciences, 353(1377), 1851-1859. 